\title{
Academic Librarians' Experiences and Perceptions on Mental Illness Stigma and the Workplace
}

\section{Erin Burns and Kristin E.C. Green}

Research has been conducted within academia about faculty members and students who have experienced mental illness from a variety of theoretical perspectives, including disability studies. While this research acknowledges that the stigma surrounding mental illness keeps people from sharing their experiences, there has not been research that focused specifically on librarians in higher education. This study sought to determine if mental illness stigma affects academic librarians and their professional environments, including teaching and providing services for students, using a survey modeled on one from the psychological literature. The responses revealed that stigma greatly influences academic librarians, particularly with regard to disclosure. An allowance for disclosure without the fear of stigmatization would not only help librarians but would also help other members of our academic communities. Sharing these survey results can begin to fill a gap that exists in the literature between librarians experiencing mental illness, the stigma that they experience because of it, and changing our academic culture.

\section{Introduction}

Trigger Warning: Before discussing this research, it is important to issue this trigger warning. Some survey participants describe what experiencing their mental illness is like and discuss their experiences dealing with stigma. In one instance, a respondent revealed experiencing the loss of someone to suicide. If these comments or descriptions might trigger you, please remember your self-care. Additionally, to protect participants' anonymity, any potentially identifying information has been removed from the quoted responses.

Librarians, like other service professionals, are guided to be compassionate and understanding about patron needs. In order to discuss sensitive issues without offending patrons, the term "invisible disabilities" has been used to describe those who may be suffering from a mental illness or other disability that may lack visible social cues. However, an unintentional consequence of using this term is the establishment of a dichotomy between the visible and invisible

\footnotetext{
${ }^{*}$ Erin Burns is Reference and Instruction Librarian in the Lartz Memorial Library at Penn State Shenango; email: emb28@psu.edu. Kristin E.C. Green is Reference and Instruction Librarian at Penn State Scranton; email: kristin. green@psu.edu. @2019 Eric Burns and Kristin E.C. Green, Attribution-NonCommercial (http://creativecommons. org/licenses/by-nc/4.0/) CC BY-NC.
} 
social cues. The field of disability studies, based in social justice, describes this dichotomy as problematic, as it creates an assumption about our patrons. ${ }^{1}$ This dichotomy places the onus of being visible on the person who is "different" from the cultural "norm" and assumes that something needs to be fixed about that person - not the surrounding institutions and culture. ${ }^{2}$ This can be highly problematic due to the historical use of disability to justify discrimination against women, people of color, and immigrant groups. ${ }^{3}$ Disability studies allows us to think outside of clinical, medical, and therapeutic perspectives on disability, as it provides a context for how disability is defined and represented in society. ${ }^{4}$ There may not currently be an easier way to discuss mental illness as other than as part of "invisible disabilities," yet sharing these research results may help make the invisible more visible.

This visible versus invisible dichotomy gets applied to those within the profession as well. The lack of social cues, as well as social and cultural constructs about disabilities (including mental illness), lend themselves to stigma and stigmatizing behavior. Stigma is a set of prejudices that draw their basis from the stereotypes that use some social cues to signal perceived social categorization and elicit emotionally driven responses, usually negative, toward the people who exhibit these cues. ${ }^{5}$ The lack of visibility of many of these cues, or marks, associated with mental illness poses an inherent contributing factor to the limited scope of an understanding of mental illness. Conversely, the visibility of some associated cues such as signs of a panic attack, auditory delusions, perceived skill deficits, or aspects of an individual's appearance can contribute to prejudice against mental illness and continued discrimination. ${ }^{6}$ This dichotomy of invisible and visible marks together feed into a negative stereotyping cycle of those with mental illness, who themselves may go to greater lengths to hide symptoms from the people in their lives, perpetuating a self-stigmatization cycle in addition to public and institutional stigma that they might encounter and seek to avoid.

This study attempted to understand the stigma and address a gap in the literature about how these librarians, many of whom are faculty on a tenure track, may experience mental illness stigma in their professional environments. While the study used a scale from the psychological literature, the field of disability studies provides a broader context to interpreting the results.

\section{Literature Review}

When Margaret Price wrote Mad at School in 2011, it was "the first book to use a disability-studies perspective to focus on the ways that mental disabilities impact academic culture at institutions of higher education."7 Price focused on rectifying the "omission/demonization/fetishization/ infantilization of mental disability in academic discourse" and asserted that mental illness is "no 'add-and-stir' problem, for it strikes at the core of the presumption of most educational theories: by definition this subject may be neither rational nor 'critical' in a normative sense," and adds to the complexity of understanding others' experiences. ${ }^{8}$ Price's more recent research has focused on accommodations in the workplace, disclosure in the academic work environment, and what barriers exist to seeking help. ${ }^{9}$ The research team found that, of their sample, most faculty with mental illness (Price uses mental illness and mental disability interchangeably) lack familiarity with accommodations that are available to them and tend not to request accommodation. A range of experiences was reported regarding disclosure, with many reporting that disclosure was more positive than neutral or negative, and that the most important supports for faculty were spouses or significant others, friends, family members, as well as colleagues on and off campus, while 
the least significant supports were supervisors, professional organizations, or on-campus mental health services. ${ }^{10}$ However, there is an inherent challenge to seeking accommodation - that "to obtain accommodation, a person with a mental disability must disclose; but the act of disclosure itself may bring about stigmatization and retaliation." 11 Moreover, stigma "plays a critical role in faculty members' work lives. Members of the academic workforce-administration as well as faculty and staff-must focus not only on the needs of individual disabled people, but also on the environments and attitudes that are constructed within universities."12

Other academics have written personal stories about their experiences with their illnesses and the academy, as one well-noted book of autopathographies demonstrates. ${ }^{13}$ Rochelle Skogen's autopathography spoke of stigma in her essay about mental illness. Skogen argues that, when university professors conceal diagnoses, they might believe that they are free of stigma, but that freedom is an illusion. ${ }^{14}$ Using the language of emancipation, Skogen suggests that the illusion is dependent on the goodwill of the would-be emancipators. By putting themselves and their work out for judgment by peers, faculty members may feel exceedingly vulnerable, which feeds into a self-stigmatizing cycle. ${ }^{15}$ She questions "how might professors' hard-earned reputations be impacted if their peers and the public suddenly became aware that they suffered from a severe mental illness? While it is impossible to predict how others will react, most of us will not take the chance of finding out."16

Peter Railton, a distinguished professor of philosophy at the University of Michigan, spoke in 2015 about his own struggles with disclosure and the fear of stigmatization: "I know what has held me back all these years. Would people think less of me? Would I seem to be tainted, reduced in their eyes, someone with an inner failing whom no one would want to hire or with whom no one would want to marry or have children? Would even friends start tiptoeing around my psyche? Would colleagues trust me with responsibility?"17

Academic librarians have just begun participating in these conversations. A recent article in College $\mathcal{E}$ Research Libraries discusses the impact of the systemic workplace barriers that face academic librarians who have disabilities. ${ }^{18}$ Schomberg's chapter in the new The Politics of Theory and the Practice of Critical Librarianship discusses disability in librarianship and addresses aspects of critical disability studies. ${ }^{19}$ Maria T. Accardi, author of Feminist Pedagogy and the Feminist Reference Desk, has spoken of recognizing the need for help when realizing that her depression was not "burnout." ${ }^{20}$ Further conversations have been taking place on social media platforms, including those on the Facebook group called Library Think Tank (ALATT) and within various Twitter threads about mental health and mental illness awareness campaigns. For example, an Association of College and Research Libraries blog by Maura Smale mentioned \#LISMentalHealth week and also examined the kinds of mental health issues graduate students in library programs may be facing.

Similar conversations also take place within the academic culture itself. Graduate students and doctoral candidates have been the focus of research on stress, anxiety, and depression rates. These studies advocate for policy interventions that include mentor training and work-life balance initiatives. ${ }^{21}$ Non-tenure-track faculty have significant stress, anxiety, and depression related specifically to their positions and the nature of fixed-term faculty contracts. ${ }^{22}$ Tenured and tenuretrack faculty are not exempt from these issues either. ${ }^{23}$ Stigma is acknowledged frequently within these studies and within these various online discussion forums. The social media commentary, research studies, and online forum discussions demonstrate that the fears surrounding cultural acceptability, failure, and inadequacy are ever-present concerns that directly impact self-stigma. 
More broadly, stigma conversations occur within academic psychological communities. Stigma and Health, a journal edited by Peter Corrigan, who has researched aspects of stigma since the 1990s, features articles that deal with the many kinds of stigma. He has described a truism "that stigma is a complex phenomenon that is understandable at many levels." 24 Stigma can manifest itself in an individual's life through four interrelated dimensions of interpersonal interaction, public imagery of mental illness, structural discrimination, and access to social roles. ${ }^{25}$ These different dimensions of stigma are seen as more significant depending on the perspective of the viewer as either an individual with mental illness, a loved one of an individual with an illness, or those who work with people who suffer from mental illness. ${ }^{26}$ Individuals with mental illness find the access, or lack of access, to social roles followed by interpersonal interaction the most directly significant dimensions of stigma to their personal well-being. ${ }^{27}$ The two stigma dimensions of accessing social roles and interpersonal interactions are also the two most prevalent in a workplace environment. Yet, due to the nature of librarianship and the library's place within society, a librarian with a mental illness may have increased exposure to the other two dimensions of stigma, public imagery of mental illness and structural discrimination, compared to some other professions. Additionally, academic libraries function within institutions of higher education, which adds another complex layer of social and structural stigma to be considered.

Measuring something as culturally noticeable and deeply felt as stigma is challenging, but the psychological literature has some measures. ${ }^{28}$ Studies have shown that people do experience stigma and that experiencing or holding negative stereotypes about one's own mental illness will have harmful effects on their self-esteem. Conversely, those with a higher self-esteem may experience less stigma. ${ }^{29}$ However, the subject of stigma is very complex and, if seen through the lens of disability studies, is another social construct in which those with disabilities, including mental illness, experience the world.

\section{Survey Creation and Distribution}

A British psychological team developed what they hoped would turn into a standardized measure of mental illness stigma. ${ }^{30}$ The team used qualitative data from interviews with mental health service users to develop a pilot scale with forty-two questions. Their final scale had a three-factor structure: the first factor focuses on concerns around discrimination, the second factor focuses on disclosure, and the third factor focuses on self-esteem. For their survey, stigma scale scores were negatively correlated with self-esteem as a whole. Because this survey was easily adaptable to distribution in an online environment, several parts were chosen for use in this study, and questions were repurposed for the academic library work environment.

After Institutional Review Board approval was granted, this survey was designed so that all respondents were free to abstain from any question, with the exceptions of their initial consent and a query to determine self-identification as an academic librarian. A statement referring for help was included, in the event a participant felt triggered by any aspect of the survey. The study was conducted without collecting any personally identifying information; it purposefully did not ask about gender or race demographics, as it was felt that there might be a possibility of identifying responses. To effectively target academic librarians specifically, the survey was distributed to college- and university-related American Library Association listservs with the assumption that many professionally engaged librarians would most likely be members. A cross-section of people who worked at different types of colleges was desir- 
able, and these listservs would be one such way of gathering a response. The specific listservs employed were the Information Literacy Instruction Section (ili-1@lists.ala.org), College Libraries (collib-@lists.ala.org), Library Administrators (libadmin@lists.ala.org), University Library Services (uls@lists.ala.org), and Reference and User Services (rusa@lists.ala.org). The survey was open for a one-month duration in 2016 between August and September.

\section{Survey Results}

The first page of the survey was a consent form and an agreement to participate. Five hundred fifty people agreed to participate in the survey, with only one declining to participate from the onset. This respondent was shown no questions and taken to the end of the survey. Another respondent asked that their survey not be included, and we subsequently withdrew that survey response, for a total of 549 respondents. Information from unfinished responses was included.

While the age of respondents varied, more than half of respondents were between the ages of 25 and 44 . Many of the respondents had worked fewer than or up to six years in their current positions at an academic library. One hundred eighty identified as tenured or on the tenure track, while 346 identified as nontenured and not on the tenure track.

Respondents were asked if they had ever been formally diagnosed with a mental illness. More than half of the respondents answered affirmatively. For those who responded with a "yes" or "maybe," the survey allowed for the person to voluntarily describe their mental illness diagnosis. Out of 311 people who wrote in, 222 said depression or a form of depression,

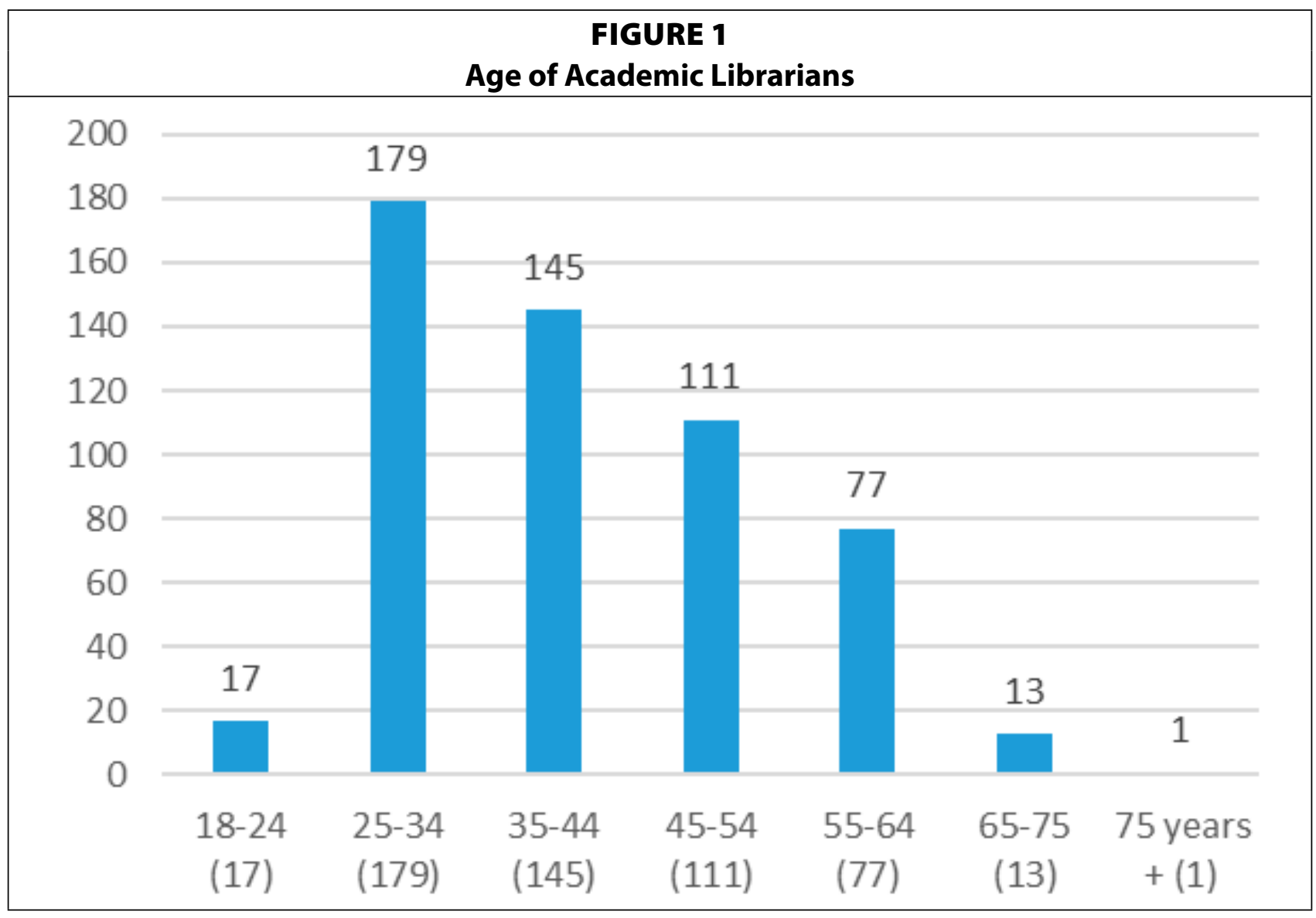




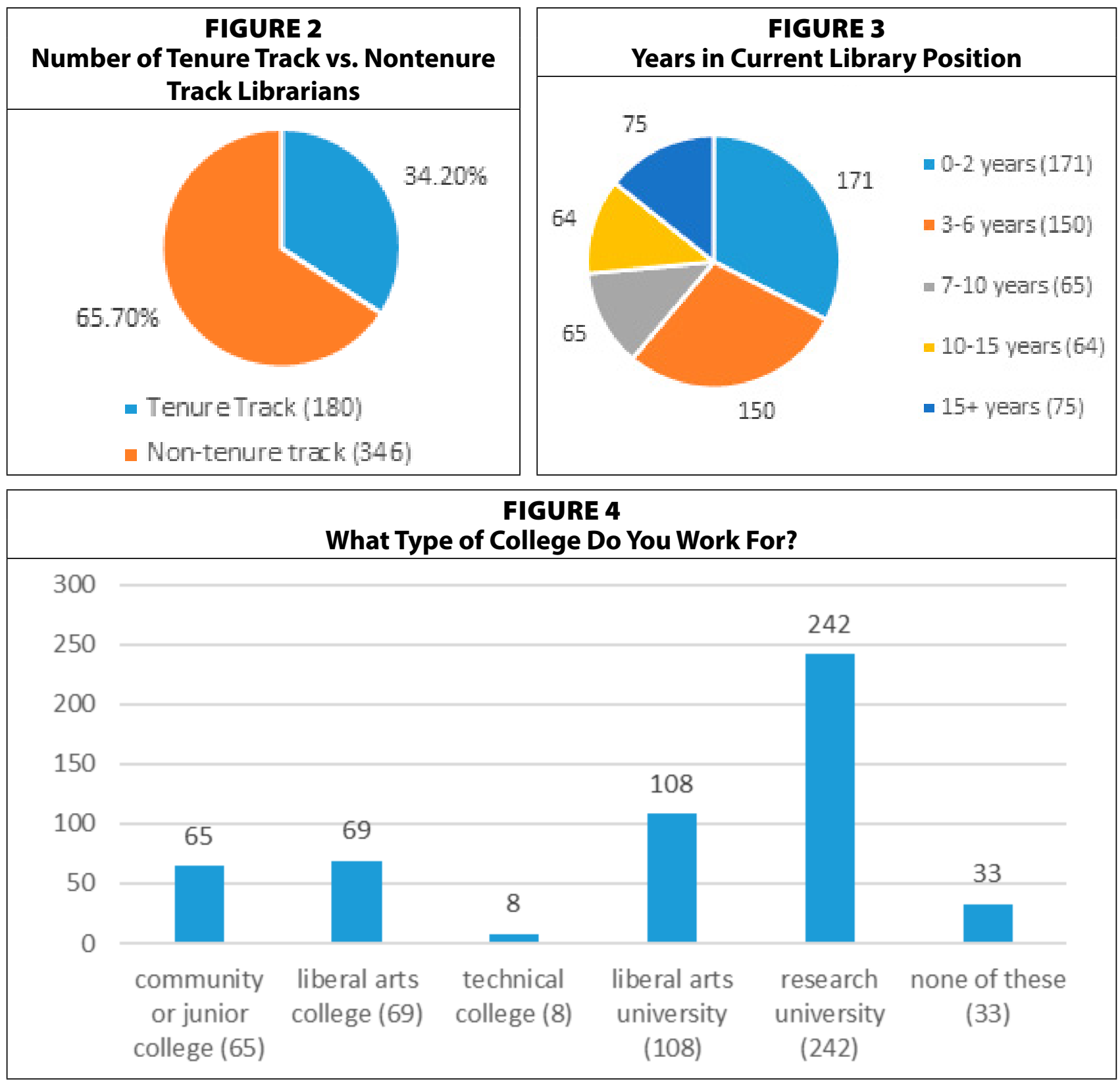

including but not limited to moderate, mild, chronic, severe, dysthymia, and melancholia. Included in those 222 were four respondents who mentioned postpartum depression specifically. One hundred thirty-nine mentioned anxiety, including but not limited to general anxiety disorder (GAD), panic attacks, panic disorders, and social anxiety. When combined with depression (comorbidity), approximately 40 percent responded that they have or have had both depression and anxiety. Other diagnoses included:

- post-traumatic stress disorder (PTSD) or post-traumatic stress syndrome (PTSS), 22

- obsessive compulsive disorder (OCD) or hoarding, 19

- bipolar, two with "possible" bipolar, 29

- eating disorders including bulimia, anorexia, and overeating, 7

- attention deficit disorder (ADD) or attention deficit hyperactivity disorder (ADHD), 4

- autistic spectrum, 2

- epileptic, 2 
Other disorders mentioned:

- dissociative disorder

- personality disorder

- adjustment disorder

- addictions

- body dysmorphic disorder (BDD)

- borderline personality disorder

- schizoaffective disorder

- gender identity disorder (GID)

- Asperger's syndrome

Three respondents felt unsure whether they had been diagnosed with a mental illness. When asked if they had received any type of counseling without being diagnosed, 320 (63\%) said "yes," while 186 (37\%) said "no." Many academic librarians felt that their mental illness

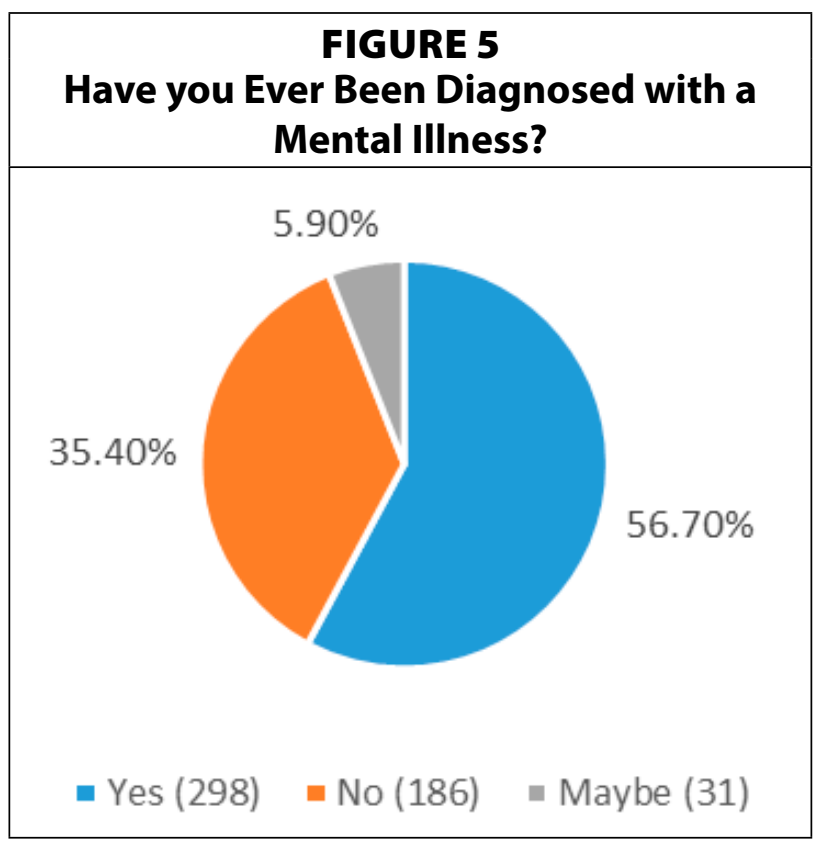
did affect their work, and almost 40 percent of respondents have taken off from work for their mental illness, while approximately 28 percent have received paid release time from work to recover from their mental illness. Approximately 8 percent have considered their mental illness a disability.

Out of 474 respondents, only 22 were granted Family Medical Leave Act time to recover from their mental health condition. However, 69 people answered that they received other kinds of workplace assistance. When asked to describe what type of help they received, the most common types were: employee assistance programming, counseling and therapy, health insurance, office accommodations, mindfulness classes, flexibility with work schedules, and compassionate supervisors and coworkers. Additionally, a few librarians mentioned that they asked for and received America with Disabilities Act accommodations for their mental illness.
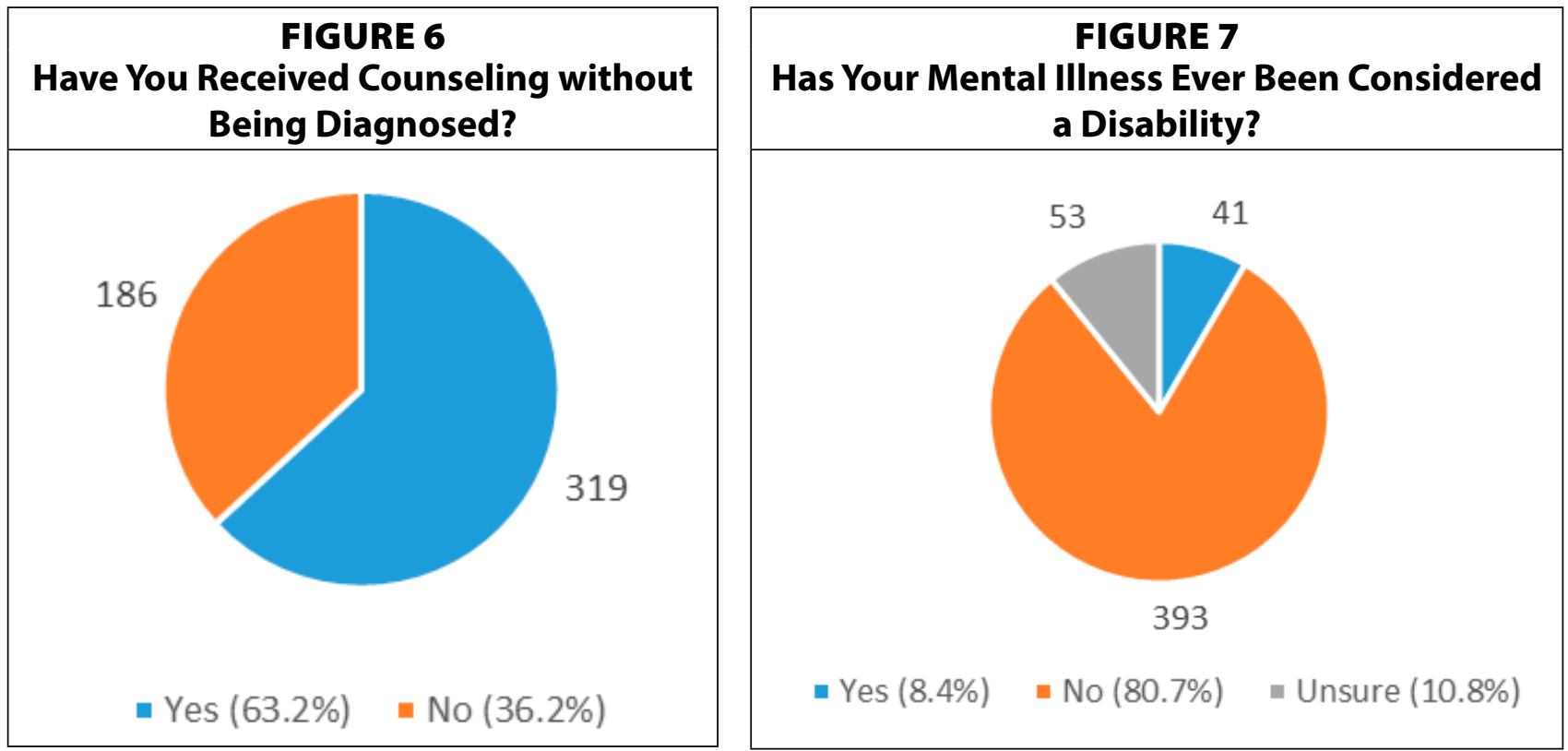


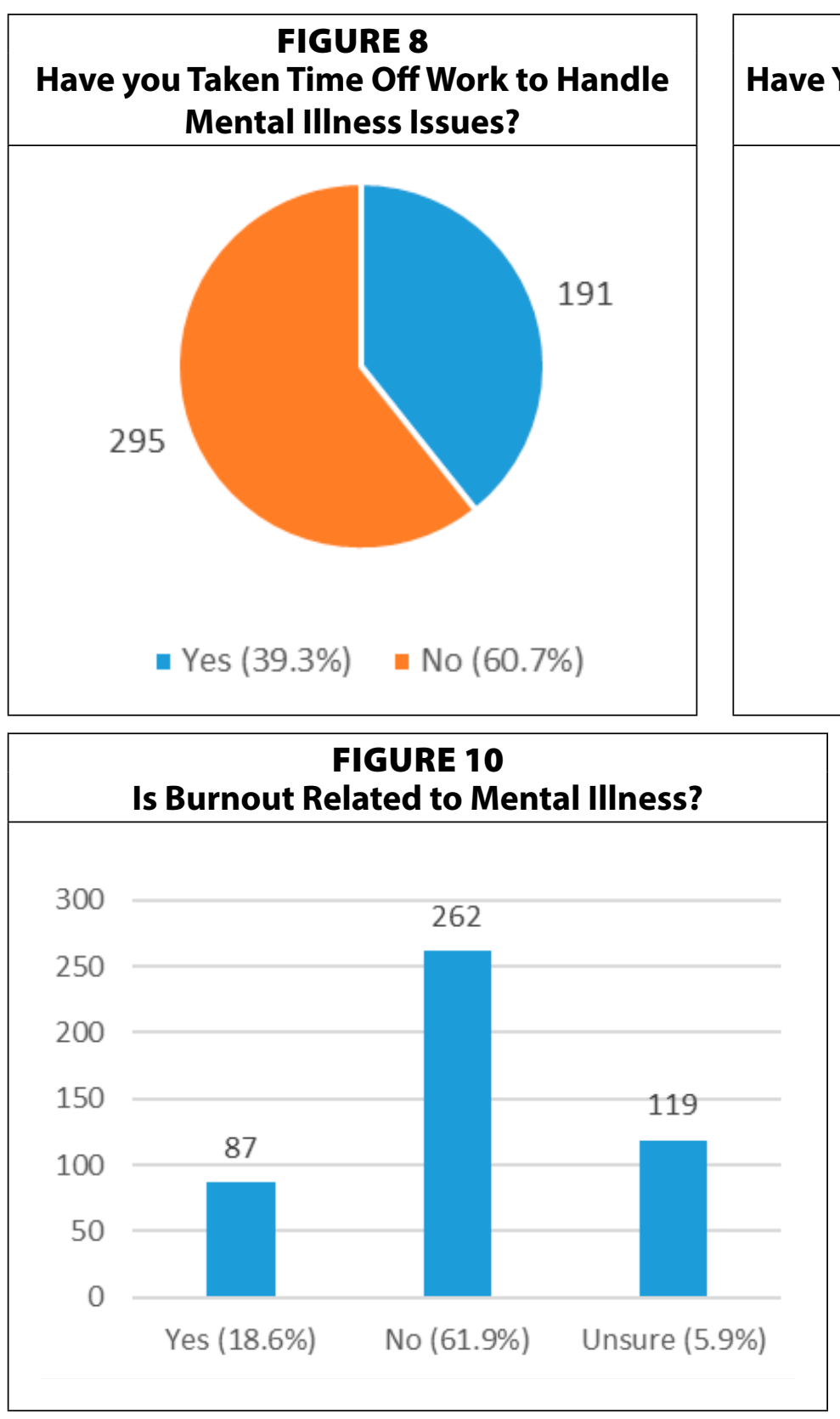

FIGURE 9

Have You Received Paid Time Off to Recover from Mental Illness?

341

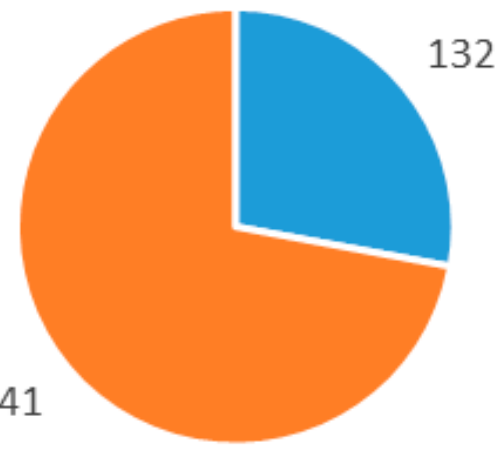

— Yes $(27.9 \%)$ ॥ No (72.1\%)

Respondents were asked if burnout could be related to their mental illness. Burnout was defined using the Mayo Clinic definition: "to become or cause to become exhausted through overwork." A follow-up was then asked to those who had responded either "yes" or "unsure." While respondents who shared their opinions about burnout and mental illness said that stressful work environments could sometimes exacerbate their mental illness, they also agreed that these environments were not necessarily the cause of their mental illness. Many of the words they used to describe burnout in relation to their mental illness symptoms included "triggers," "amplifies," and "more susceptible." Other workplace issues included "lack of support," "toxic" environments, and bullying by coworkers or administrators.

"Anxiety triggered by my work, by understaffing at work, etc. becomes exhausting, which may be contributing to burnout as a separate issue. They are sometimes hard for me to tell apart." 
"IMHO, libraries and college expect a lot of work from their employees. More work is being done with fewer resources (people, money, services, etc.) As a result and also due to tenure possibilities, there is a certain pressure to perform well and at a very high level in numerous areas. There is not enough time to do all of the work on a weekly basis or daily basis so work has to come home for the weekend and work is completed during evenings after work hours or else I stay late. I feel that all of this wears on me and has contributed to my burnout. I'm not sure which comes first necessarily though, is it my possible diagnosis, burnout due to job or a combination of the two. Probably the latter is most true."

"I know that I have felt burned out before and I think I neglected some of the symptoms of burnout because I attributed it to my anxiety. I'm tired and overwhelmed because of my brain, not because I am working at a dysfunctional place with a poor worklife balance. Burnout then exacerbates my anxiety-a vicious cycle. Burnout leads to poor self-care, which leads to triggering anxiety (not eating right, not sleeping etc.)."

"Stress at large is a huge contributor to symptoms for both of my [diagnoses], so any type of stress can be problematic. However, I will say burnout does amplify many of my symptoms and potentially has been the cause of several days I have needed to take due to mental health issues."

"I believe the burnout that I have experienced has a direct connection to my anxiety and depression. As a librarian who is introverted, yet working as an instruction librarian and outreach person, I am constantly battling my insecurities and worries, but I find job satisfaction in doing these sorts of tasks. I also take pride in what I can and have achieved outside my comfort zone despite my natural inclination to shy away. This can take a toll on me when I don't balance my rest with my activity. I don't believe that I am unbelievably affected by my anxiety though. I feel that I have worked quite hard to develop coping mechanisms and strategies to be even more successful."

"PTSD is an anxiety disorder, which means a great deal of my mental/emotional energy is devoted to maintaining an emotional equilibrium/coping with constant anxiety and any spikes in my distress level whether related to my trauma (i.e. certain topics in the news or scholarly communication) or not (i.e. raging impostor syndrome in my new position). Consequently, mental or emotional burnout is never very far away, and while my work, solving problems, designing and implementing inclusive outreach initiatives, and just helping my campus community can be a distraction and very fulfilling, it can also require a great deal of emotional labor, particularly as the only queer woman of color in my library."

Participants were asked if they received training to accommodate mentally ill patrons or students, and the types of training they received: 128 librarians mentioned receiving training, 297 said no, and 41 said maybe. Five librarians wrote that they received a degree in counseling or clinical psychology, or previously worked as a social worker or crisis counselor. However, the most common type of training mentioned, by 16 respondents, was workshops on recognition and referral to appropriate campus departments for assistance. The program with a 
specific name most mentioned, by 10 respondents, was "Mental Health First Aid," which can be conducted as either a 2-hour workshop or an 8-hour workshop. Other programs cited were:

- "students in crisis" or "distress," 11

- recognize suicidal behavior and suicide prevention, 8

- "dealing with difficult people," 5

- behavior intervention for safety and security, 7

- active shooter training, 2

These trainings were facilitated by a variety of campus services, including university or campus counseling departments, Campus Disability Services, Human Resources trainings, and the campus Students with Disabilities group.

The survey tool separated library administrators' responses. Of those who identified as administrators, almost two-thirds said they did not receive any mental illness training.
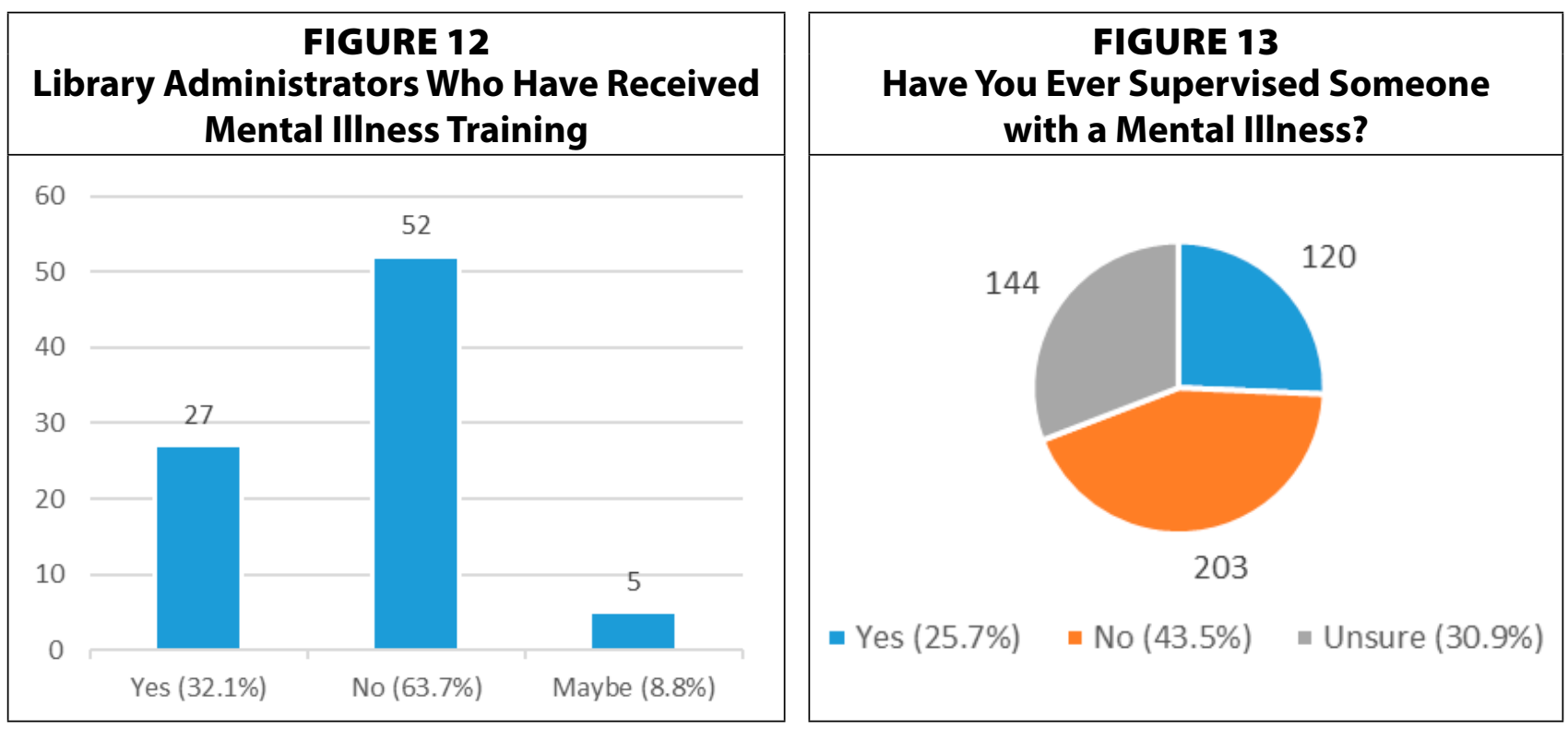

The survey also asked librarians if they had supervised someone with a mental illness, as a librarian can often have supervisory responsibility without being an administrator. Onehundred twenty had supervised someone with a mental illness, but another 144 were unsure if they had or not.

Using a Likert scale based on King et al., respondents rated questions on mental illness and self-esteem with regard to aspects of their jobs. ${ }^{31}$

Nearly 40 percent said that people are understanding of their mental illness, and 83 percent "agree" or "strongly agree" that having a mental illness made them more understanding and empathetic. With regard to their work and issues of self-esteem, 45 percent "agree" or "strongly agree" that their mental illness allowed them to reflect more on their teaching, and 35 percent "agree" or "strongly agree" that their mental illness allowed them to be a better librarian. However, academic librarians "disagree" or "strongly disagree" with the statement that the general public is understanding of people with mental illness, and 55 percent "agree" or "strongly agree" that other people's reactions to mental illness keeps them from disclosing their own mental illness to others. 

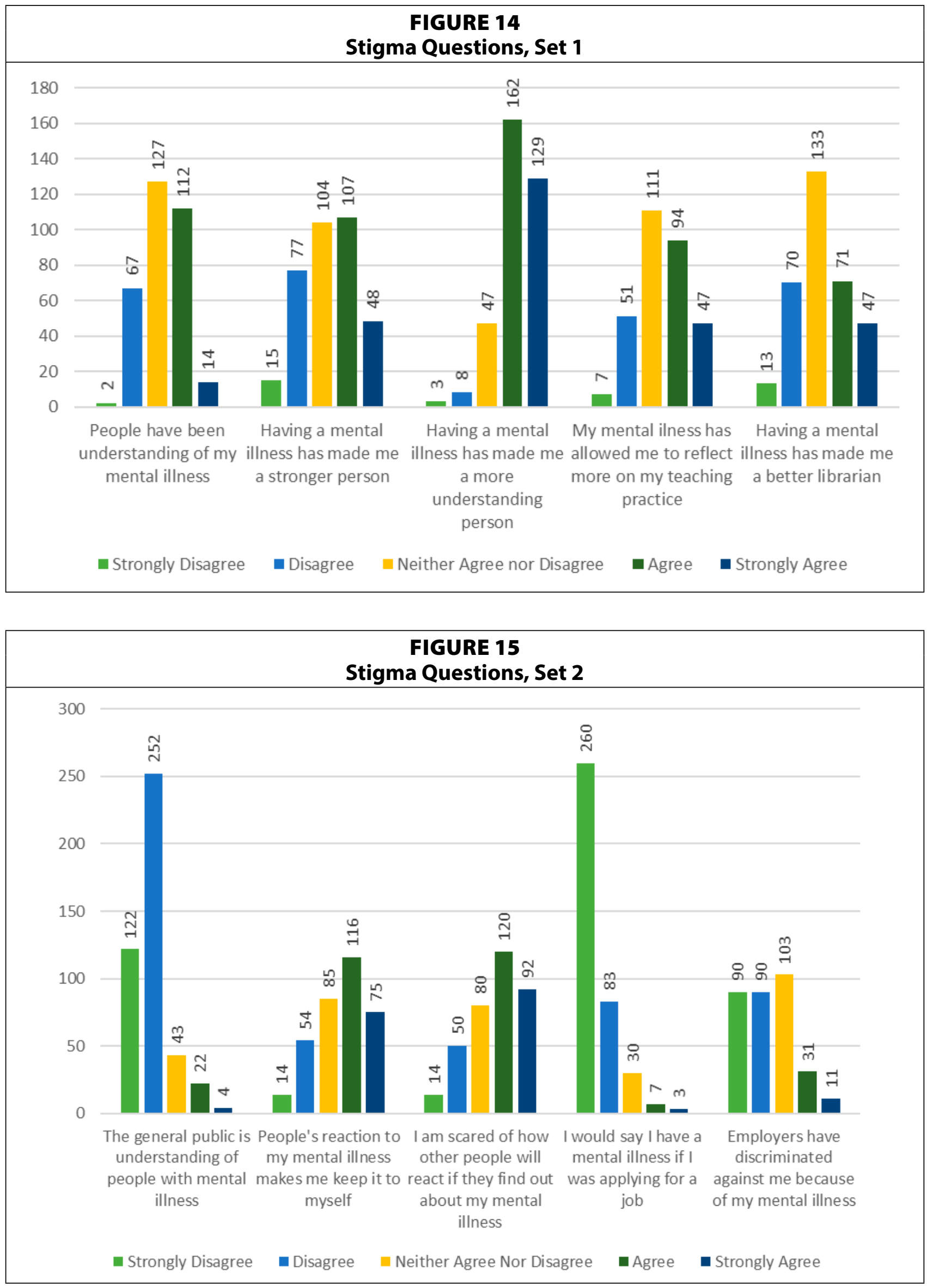
Nearly 60 percent "agree" or "strongly agree" that they are scared of how other people might react to their mental illness. There were 64 librarians who "agree[d]" or "strongly agree[d]" that others' reactions to mental illness makes them reticent to disclose their mental illness. A select few, approximately 2 percent, would disclose their mental illness with a potential employer, while approximately 13 percent "agree" or "strongly agree" that they had been discriminated against by employers because of their mental illness. These responses regarding the discrimination and disclosure demonstrate that there is still a fear of stigmatization, though librarians felt positively about certain aspects of their jobs in relation to their mental illness.

This fear of stigmatization and shame revealed itself in participants' comments. Many people felt that they could not share their mental health diagnosis with their coworkers or supervisors. Librarians felt that, if they disclosed, they might be expected to "work harder." They could be seen as suspicious and "taking advantage of the system." Others wrote about the fear of others finding out causing anxiety. One librarian's supervisor had made an insensitive remark about the reasons this individual was staying home, while implying this individual was being dishonest. Because of these comments, the librarian feels unable to ask to be able to work from home on the days that their mental illness might be more debilitating. If person could be more comfortable talking to their supervisor, perhaps it would be easier to ask for such accommodations. Many other comments echoed this sentiment.

"Our country has a huge mental illness problem wherein we tend to ignore it as much as possible. Although I have mental illness, I may also be part of the problem as I have not revealed my mental illnesses with my administrators or in any previous position. Because of media portrayal and the reactions I have had in my personal life (including things like you can't be OCD because your space is messy...), I do not feel comfortable coming 'out' about it though I sometimes think it would help others understand me and my methods."

"They can't fire me because of a medical diagnosis, but my coworkers sure can make my life hell if they only knew by their actions, assumptions, whispers, snide remarks, etc."

"People see the worst on television and think all mentally ill people are like that. Not all mentally ill people are violent or destructive - there is a stereotype for you."

"We work diligently to support each other at work and help each other through difficult times. We often do this in hiding from the other library staff because of the stigma. We desperately wish that our administration would recognize our medical conditions and work to learn about and support us."

"I certainly don't advertise my depression because I believe it would be seen by some as a weakness and would be held against me. Calling it 'mental illness' certainly does not help because I think people equate it with not being able to function and this is not always the case."

"They don't know how bad severe depression can be, and have looked down on me for my unprofessional behavior." 
"Depression has come a long way in being accepted, but as with all mental illnesses, everyone is uncomfortable talking about it. There is definitely a stigma with having any 'weakness' or mental illness. It makes a person build walls and separate themselves from the rest of the group."

Further reflections were more positive or neutral in nature and tone. Some mentioned knowing that coworkers "who have had various battles with mental illness" made coping easier. One "felt most comfortable at a job were there were spaces and people to talk to about mental illness." A few respondents wrote about being able to discuss medications with their coworkers or supervisors who were going through something similar.

"It is a risk to be open about mental illness and I've been extremely lucky in my new role... When I decided, for the first time in my life, to tell my employer here about my mental illness, I was overwhelmed by the support and understanding it was met with. In fact, after I finished explaining to my boss that I had bipolar 2 disorder, she revealed to me that she does as well. It was a major risk to talk with her openly about this issue, but I'm so glad I took that risk. My work environment transformed and my feelings about being open about it have deepened. I'm still not going to be advertising it openly to every person I meet because there is a major stigma attached to mental illness, and not everyone is as accepting as my boss - but I'm feeling like one day I may be able to be completely open about it. We'll see, but I've learned that an environment of support and understanding is vital for creating a safe place. It was a life changing risk to open up about my mental health at work, and I don't for a second regret it."

"I've been lucky and well-supported. The issues I've had to deal with have been comparably mild. But I also hid a lot of how I was affected and I feel like I needed to do that to progress in my field. Mental illness is difficult to deal with because I' $m$ very aware of this prevailing sense that everyone has to deal with hard things and that 'good' employees should suck it up and tough it out or just be mentally tougher in general."

"Considering the nature of my mental illness, I am extremely high-functioning for someone with my diagnosis. My psychologist is forever telling me that most persons with [disorder name removed] would be unable to function in a faculty librarian tenured position with the level of ambiguity and stress I deal with."

Respondents also mentioned specifically the intersection between their work as librarians, and being able to work with students one-on-one and providing empathy and compassion to their communities.

"Obviously I don't share my depression; instead, I try to talk about what empathy looks like as an observable behavior."

"I do think, however, that we academic librarians work with and offer emotional as well as academic support to students who might have a mental illness, although we often do 
so without specific training. Librarians' education and experience in providing reference services to students predisposes us to be active and responsive listeners. By working oneon-one with students, we likely encounter some who have mental illnesses that may or may not be evident to us. But, our commitment to treating all students with respect and regard for their academic success makes it possible for us to offer the kind of support that students with mental illness need without [our] being aware of their illness."

"Having anxiety has helped me to better able to deal with students who have anxiety, where it's chronic anxiety or situational anxiety. A lot of students have library anxiety and I am very good at dealing with that and putting them at ease, but I have also dealt with students who have chronic anxiety and end up at the reference desk in tears due to the level of anxiety they are feeling. And I am very good at it."

However, as noted in the comments, librarians still feel like there is a lot of work left to do to challenge stigma.

"I think we have an extraordinary amount of work to do still to challenge the ableist and classist treatment of mental illness in academic and public libraries... and I wish we could hold more space for discussions on the intersections of grief and trauma between researchers and archivists."

"While I suffered from bouts of depression due to personal reasons (not connected with work), I received a lot of support and understanding from my supervisor and colleagues. My health insurance also allowed me to be in therapy for three years and I was able to take paid sick leave for it. I do think it's important for colleges/universities to offer regular training on dealing with mental illness and being an empathetic and supportive presence for people with a mental illness."

"Gender identity disorder is not being addressed by libraries, administration in a way that is appropriate and correct."

"This needs to be seen as just another illness and treated as such. Support needs to be easy to find with no repercussions. Reasonable accommodation and counseling need to be available."

"its like being a 'working mom' in a workplace where very few are moms and do not understand what its like to juggle professional work/home 'work' and other things that can pop up in a moments notice. I work hard at my job/ stay on top of my depression/anxiety which is more biologically (hereditary) in nature and now know when its time to take a 'vacation day' when needed. (I have a different supervisor now however who as a working mom knows that some days its all overwhelming....) I will also say its made me more approachable for my student workers to talk openly about anxiety/stress and depression. after a trust is built, $i$ let them know I really do know and understand. my adult daughter has GAD (sometimes to extreme) and how we work together. What really hurts is when 
a student tells me their parents are not understanding and will not help them seek treatment. I try to help them find treatment on their own (they are all over 18. they don't need permission). I lost a fantastic student (person) last year to suicide. I'm still hurting over this-esp when I know he had sought treatment but when he went home is when he unraveled. We really need to step up mental health awareness at all levels and make it on the forefront - there is very little to no mental healthcare in rural america."

"While I don't necessarily feel that I'd be stigmatized for mental illness in my workplace, it is not something that is spoken of and it is not really an environment where there is a safety net for being transparent about it. Mental health issues are all around us, but as librarians we seem to avoid talking about them and how they affect our work both within the organization and when working with patrons. I have freely shared with a number of colleagues that I take an antidepressant, but I am not sure this transparency is really in my best interest (I tend to be honest to a fault). It would be great to work in an environment where mental health issue were discussed and not hidden (especially since it is an extremely prevalent issue all around us and people are suffering); librarians could really lead the way on removing barriers and stigmas related to mental health problems with information literacy on the topic. I am really thankful that you are researching this topic and hope that I can read about what you found at some point. Really a lot of things to think about such how libraries deal with traumatic events in communities, such as the Orlando shooting, that have a profound effect on the mental health of members in communities and the colleges/universities around them in ways we should not ignore."

"I am well established in my current position - I have been here for 22 years, been tenured for over 15 years, and am currently a dept head - so I go out of my way to talk about my illness and mental illness in general in order to promote understanding and reduce the stigma, especially to help people who may be in a more vulnerable position. I find that most people I encounter at the library are willing to be flexible about it once they learn of it, but are generally uninformed on the issues."

"I have bipolar disorder, and been stable for several years. Administrators at my law school often refer students who are struggling with their mental disorders to me. I can share my past, and the hell that I dealt with before I was diagnosed, but they can also see that medication and healthy living will win out. I'm their instructor and librarian, so they see me every day. My Director calls me the poster child for what managed mental illness looks like. Plus, I'm a stigmabuster - I can talk about it when I'm asked, knowing that the stigma may be there, but I can handle it. To answer your question - the biggest effect on my work environment is that I can help everyone to understand what it is, and every year I help at least one student who is spiraling down. Law School is tough enough in the first place; they need to have someone who understands what is happening to them."

"I think this is a difficult issue that's hard to quantify since there are so many factors of a person that [affect] why they would or would not disclose a mental illness in the workplace. Just like any other illness, there's a time and place for disclosing mental illness in the workplace along with personal preference, privacy, extrovert/introvert, etc. There's 
also varying power structures in place (within the library, university, etc.) that [affect] whether or not I disclose my anxiety disorder. While I think this is a very, very important topic to bring awareness to, I think it's very complicated and motivations are very different from person to person (and disorder to disorder)."

"1) Trigger warnings matter, and stigma around them and those with mental illnesses that need them (like PTSD) tends to dismiss them as political correctness run amok. In reality, trigger warnings are exactly the same as allergen warnings and every bit as vital to the health and functionality of those who require them-students and librarians alike. 2) There is a difference between mental illness and neurodivergence/neurodiversity. Many disorders hover between the two. I would love training and workshops for librarians about identifying the needs of and assisting both kinds of patrons. 3) Stigma goes handin-hand with oppression. Libraries (and the field of librarianship) that are interested in anti-oppressive service and ethics cannot overlook mental illness and neurodiversity in their user populations and library workforce."

\section{Discussion of Results}

The most obvious finding is that there is a fear of disclosing one's own mental illness in the academic library environment. This sentiment echoes Price and others' research on faculty fears of disclosing one's mental illness status. ${ }^{32}$ Some librarians were able to disclose their mental illness to colleagues and students and could build positive relationships, which has been shown to positively impact self-esteem and help reduce feelings of stigma. ${ }^{33}$ Yet these comments clearly show there is still much work to do to destigmatize mental illness in the academic world.

Another finding of the researchers is that there are ways of reducing stigma and stigmatizing behaviors. Research has shown that trainings and workshops may have a positive impact on reducing stigma in the short term, such as Mental Health First Aid, while other types of advocacy efforts can help in the long term. ${ }^{34} \mathrm{~A}$ respondent had mentioned that making this program mandatory for all colleges and universities would help people regardless of personal prejudices. And, while behavioral threat management trainings are important for safety reasons, there is an apprehension that it can contribute to societal and institutional stigma if it is the only training an individual has in assisting someone with mental illness. An individual with mental illness is far more likely to be the victim of a crime, and accusations against them are often deflections based in stigmatization and prejudice of mental illness. ${ }^{35}$

Reducing institutional stigma specifically may be possible by providing mental health trainings that require administrator attendance. By seeing administrators attend such sessions, individuals suffering with mental illness may be more likely to disclose and seek help if needed. However, this might also not be the case. One should not feel compelled to disclose if one does not feel safe in doing so. More research could be done in this area to determine if there is a correlation between administrator training and disclosure.

Additionally, while there have been various programs that have shown that mental illness awareness helps to lessen stigma, it proves exceedingly important to recognize stigma and address it when someone views stigmatizing behaviors. Intervention in these conversations 
with colleagues, when it is apparent that an individual is being denigrated or marginalized, is a method for conducting accessibility at an individual level and allows discussion to ensue about the nature of mental illness. ${ }^{36}$ This also needs to happen at an administrative level. Many of the librarians who commented felt unable to go to their administrators for help when needed, as they felt overworked or that their voices would not be heard.

Further research could also be conducted on burnout and mental illness in the academic setting. While librarians as a group did not feel that burnout caused mental illness, research has shown that burnout can exacerbate mental illness symptoms. ${ }^{37}$ Research has also shown that sustained stress can cause depression and anxiety, and the overlap between the burnout and mental illness can be unclear at times for those seeking help and for those who might be diagnosing. ${ }^{38}$ The main symptoms of burnout-exhaustion, alienation from work activities, and reduced work performance-echo the symptoms of depression; discussing these differences would be prove beneficial to include in trainings if it is not already being included. ${ }^{39}$

As mentioned in respondent comments, other programming options include programs that librarians are more familiar with and can create themselves. Many young adult book clubs focus on the topic of mental illness in young adult literature, which may help reduce the stigma associated with mental illness. ${ }^{40}$ Programming focused on health literacies for young adults may promote and contribute to a sense of well-being. This type of programming may provide opportunities for librarians to disclose to students who may be suffering, as knowing a faculty member or librarian who may have gone through similar situations can reduce the students' fear of disclosure and self-stigmatization. Collaborating with other campus partners to develop programs with a focus on awareness and stigma also fosters an environment open to nonjudgmental disclosure, and research could be done to see if any of the programming options would reduce feelings of stigma in students or faculty and staff participants.

Furthermore, the possibility that one discloses during the job application process may be due to other factors beyond stigma, such as conducting interviews in a manner that gives all candidates an equitable opportunity. A closer examination of this topic in a follow-up study may prove insightful.

Additional research questions could have included additional aspects of self-esteem to garner a more holistic understanding of respondents' experiences. However, for this study, great care was taken to avoid collecting personally identifying information. Other kinds of societal structures may be involved in mental illness constructs in how mental illness is discussed in society and how librarians experience it. Any follow-up survey should consider collecting gender, race, and socioeconomic demographic data to explore these societal dimensions and power structures. Possible one-on-one interviews with others about their personal experiences with mental illness in academic libraries would prove valuable, as would conversations around the privileged aspect to seeking mental health help.

\section{Conclusion}

This survey was by no means exhaustive. Further research into this topic is encouraged as well as needed and could be explored as in-depth demographic research and should include individuals affected by stigma although not diagnosed with a mental illness. Replicating this survey in a few years could potentially show some change in the academic climate regarding mental illness stigma and mental health issues. While academic librarians seek out mental illness training once in their positions, it could be useful to know if library science graduate 
programs are teaching courses or hold workshops that address the topic and if this has any effect on librarians disclosing their own mental illness and feelings of self-esteem once in graduate school and the workplace. A more in-depth study on the types of trainings, how often they are offered, and if librarians are required to attend because of the service-related nature of their jobs would prove illuminating, as this kind of advocacy has been shown as critical to fighting mental illness stigma. ${ }^{41}$ If librarians, in conjunction with other campus services, can offer more trainings, workshops, and webinars, strategic awareness could be better measured within academic libraries and campus communities. While strategic awareness should not be equated with acceptance or tolerance, awareness is the first step toward eradicating stigma and its ilk.

Libraries are considered by many to be safe places, welcoming to all who use the spaces, services, and resources that they provide. The fact that many academic librarians feel unsafe to come forward speaks volumes to the work needed to make academic library spaces safe for all. University and college campus libraries strive to provide the support needed for students to achieve academic success throughout their pursuit of higher education. Thus, it is apparent that academic libraries should acknowledge the importance of also making the internal work environment a safe place for individuals with invisible disabilities such as mental illness. Schomberg mentions that any change or conversation should start with those most affected, and administrators or others should ask if it is welcome before implementing any new initiatives. ${ }^{42}$ Many strategic plans, vision and mission statements throughout institutions of higher education today call for inclusivity and fostering an understanding of differences. By advocating for inclusion and awareness, as well as trainings and initiatives within the profession of academic librarianship, a destigmatization may begin that serves to educate all individuals within the academic communities across higher education. If librarians genuinely strive to create environments of inclusion within their libraries, an allowance for disclosure of mental illness without the fear of stigmatization would not only help members of our local academic communities but librarians as well.

\section{Notes}

1. Margaret Price, Mark S. Salzer, Amber O'Shea, and Stephanie L. Kerschbaum, "Disclosure of Mental Disability by College and University Faculty: The Negotiation of Accommodations, Supports, and Barriers," Disability Studies Quarterly 37 (2017), available online at http://dsq-sds.org/article/view/5487/4653 [accessed May 10, 2018].

2. Price, Salzer, O'Shea, and Kerschbaum, "Disclosure of Mental Disability by College and University Faculty."

3. Jessica Schomberg, "Disability at Work: Libraries, Built to Exclude," in The Politics of Theory and the Practice of Critical Librarianship, eds. Karen P. Nicolson and Maura Seale (Sacramento, CA: Library Juice Press, 2018).

4. Steven J. Taylor, "Disability Studies," Encyclopedia of American Disability History, Facts on File Library of American History, ed. Susan Burch (New York, NY: Facts on File, Gale Virtual Reference Library, 2009), 286-87.

5. Patrick W. Corrigan, Jonathon E. Larson, and Sachiko A. Kuwabara, "Social Psychology of the Stigma of Mental Illness: Public and Self-Stigma Models," in Social Psychological Foundations of Clinical Psychology, eds. James E. Maddux and June Price Tangney (New York, NY: Guilford Press, 2010), 51-68.

6. Patrick W. Corrigan and Petra Kleinlein, "The Impact of Mental Illness Stigma," in On the Stigma of Mental Illness: Practical Strategies for Research and Social Change, ed. Patrick W. Corrigan (Washington, DC: American Psychological Association, 2005), 11-44.

7. Margaret Price, Mad at School: The Rhetorics of Mental Disability and Academic Life (Ann Arbor: University of Michigan Press, 2011).

8. Price, Mad at School. 

ulty."

9. Price, Salzer, O'Shea, and Kerschbaum, “Disclosure of Mental Disability by College and University Fac-

10. Price, Salzer, O'Shea, and Kerschbaum, “Disclosure of Mental Disability by College and University Faculty."

11. Price, Salzer, O'Shea, and Kerschbaum, “Disclosure of Mental Disability by College and University Faculty."

12. Price, Salzer, O'Shea, and Kerschbaum, “Disclosure of Mental Disability by College and University Faculty."

13. Illness in the Academy: A Collection of Pathographies by Academics, ed. Kimberly Meyers (West Lafayette, IN: Purdue University Press, 2011).

14. Rochelle Skogan, "'Coming into Presence' as Mentally Ill in Academia: A New Logic of Emancipation," Harvard Educational Review 82, no. 4 (2012): 491-510, 566.

15. Skogan, "'Coming into Presence' as Mentally Ill in Academia."

16. Skogan, "'Coming into Presence' as Mentally Ill in Academia."

17. Colleen Flattery, "Personal Philosophy," Inside Higher Ed website (Feb. 25, 2015), available online at https:/ www.insidehighered.com/news/2015/02/25/professors-reflections-his-battle-depression-touch-many-recentdisciplinary-meeting [accessed May 1, 2017].

18. Joanne Oud, "Systemic Workplace Barriers for Academic Librarians with Disabilities," CERL (2019), available online at https://crl.acrl.org/index.php/crl/article/view/16948 [accessed May 1, 2018].

19. Schomberg, "Disability at Work: Libraries, Built to Exclude."

20. M.T. Accardi, "When Burnout Obscures Major Depression" (blog, Jan. 18, 2016), available online at https:// librarianburnout.com/2016/01/18/when-burnout-obscures-major-depression-a-lismentalhealth-week-post/ [accessed April 2017; as of May 20, 2019 blog and link are no longer active].

21. Teresa Marie Evans, Lindsay Bira, Jazmin Beltran-Gastelum, L. Todd Weiss, and Nathan Vanderford, "Mental Health Crisis in Graduate Education: The Data and Intervention Strategies," FASEB Journal (2017), available online at www.fasebj.org/doi/10.1096/fasebj.31.1_supplement.750.7 [accessed April 14, 2018]; Marianne Di Pierro, "Mental Health and the Graduate Student Experience," Journal for Quality and Participation 40 (2017): $24-27$.

22. Gretchen M. Reevy and Grace Deason, "Predictors of Depression, Stress, and Anxiety among Non-tenure Track Faculty," Frontiers in Psychology 5 (2014): 1-17, https://doi.org/10.3389/fpsyg.2014.00701.

23. Price, Mad at School; Price, Salzer, O'Shea, and Kerschbaum, “Disclosure of Mental Disability by College and University Faculty."

24. On the Stigma of Mental Illness: Practical Strategies for Research and Social Change, ed. Patrick W. Corrigan (Washington, DC: American Psychological Association, 2005), 281-96.

25. Norman Satorius and Hugh Schulze, "Conclusions and Recommendations," in Reducing the Stigma of Mental Illness: A Report from a Global Programme of the World Psychiatric Association, (Cambridge, UK: Cambridge University Press, 2005), 152-171.

26. Satorius and Schulze, "Conclusions and Recommendations," 152-171.

27. Satorius and Schulze, "Conclusions and Recommendations," 152-171.

28 Shirli Werner, Patrick Corrigan, Nicole Dicthman, "Stigma and Intellectual Disability: A Review of Related Measures and Future Directions," Research in Developmental Disabilities (2012): 748-65.

29. Michael King et al., "The Stigma Scale: Development of a Standardised Measure of the Stigma of Mental Illness," British Journal of Psychiatry 190 (2007): 248-54. https://doi.org/10.1192/bjp.bp.106.024638.

30. King et al., "The Stigma Scale: Development of a Standardised Measure of the Stigma of Mental Illness."

31. King et al., "The Stigma Scale: Development of a Standardised Measure of the Stigma of Mental Illness."

32. Price, Salzer, O'Shea, and Kerschbaum, "Disclosure of Mental Disability by College and University Faculty."

33. Corrigan and Kleinlein, "The Impact of Mental Illness Stigma."

34. Amy C. Watson and Patrick W. Corrigan, "Challenging Public Stigma: A Targeted Approach," in On the Stigma of Mental Illness: Practical Strategies for Research and Social Change, ed. Patrick W. Corrigan (Washington, DC: American Psychological Association, 2005), 281-96.

35. Dean Burnett, "Stop Blaming Mental Illness for Violent Crimes," The Guardian (June 21, 2016), available online at https://www.theguardian.com/science/brain-flapping/2016/jun/21/stop-blaming-mental-illness-forviolent-crimes [accessed February 1, 2018].

36. Price, Mad at School.

37 Institute for Quality and Efficiency in Health Care (IQWiG), “Depression: What Is Burnout” (2017), avail- 
able online at https://www.ncbi.nlm.nih.gov/pubmedhealth/PMH0072470/ [accessed February 12, 2018].

38. IQWiG, "Depression: What Is Burnout."

39. IQWiG, "Depression: What Is Burnout."

40. Diane Scrofano, "Not as Crazy as It Seems: Discussing the New YA Literature on Mental Illness in Your Classroom or Library," Young Adult Services 15 (2012): 15-20.

41. David V. Perkins, Joshua A. Raines, Molly K. Tschopp, and Todd C. Warner, "Gainful Employment Reduces Stigma toward People Recovering from Schizophrenia," Community Mental Health Journal 45 (2009): 158-62, https://doi.org/10.1007/s10597-008-9158-3.

42. Schomberg, "Disability at Work: Libraries, Built to Exclude." 